\title{
Determinants of the Spatial Mobility of Immigrants: Evidence from Sweden
}

\section{Terance J. Rephann and Coomaren P. Vencatasawmy*}

\begin{abstract}
Foreign-born residents constitute approximately 11 percent of the Swedish population. This level has been reached after steady immigration during the postwar years and has been accompanied in recent decades with proportionately more non-European immigrants. This paper examines how these foreign born differ from native Swedes in internal migration behavior using a unique, geographically descriptive micro database. It finds that they differ, in part, because of the role that the size of foreign-born communities plays in both the decision to migrate and choice of destination. The implications of these results for public policy, regional economic growth, and regional economicdemographic modeling are discussed.
\end{abstract}

\section{INTRODUCTION}

Foreign-born residents made up approximately 11 percent of the Swedish population in 1995. This level was reached after a surge in immigration during the postwar years (see Figure 1) that has become increasingly diverse in recent years (see Figure 2). Swedish immigration law has undergone three distinct phases that have affected both the volume and diversity of newcomers. After the World War II, Sweden witnessed an influx of workers from other European countries who were recruited to fill vacant industrial slots, followed in 1954 by an agreement among the Nordic countries to create a common labor market that resulted in increased Nordic immigration. During the 1960s, because of tightening labor market conditions in northern Europe, workers were recruited from farther afield, primarily from southern Europe but also from nearby Finland. In 1967, however, Sweden introduced a more restrictive immigration law and labor recruitment from abroad was severely curtailed. Afterwards, an increasing number of immigrants were refugees from war-torn or repressive countries in Asia, Africa, Latin America, and the Balkans.

The changing volume and origins of the immigrant stream have ramifications for regional economic and demographic development in Sweden for several reasons. First, immigrant settlement patterns are somewhat different from those of native Swedes (Borgegård, Håkansson, and Müller 1996; Borgegård and Håkansson

*Senior Scientist, Spatial Modelling Centre, Kiruna, Sweden; and Senior Scientist, Department of Forest Resource Management and Geomatics, Swedish University of Agricultural Sciences, Umeå, Sweden. This research was supported by funding from the European Community, European Regional Development Fund. The views expressed in the article are those of the authors alone. 
1997). Second, immigrant ${ }^{1}$ internal migration patterns, following arrival in Sweden, differ from native Swedes (Andersson 1996). Furthermore, these patterns vary by immigrant characteristics, such as country of origin, year of arrival, and

\section{FIGURE 1}

Immigration to Sweden, 1880-1998

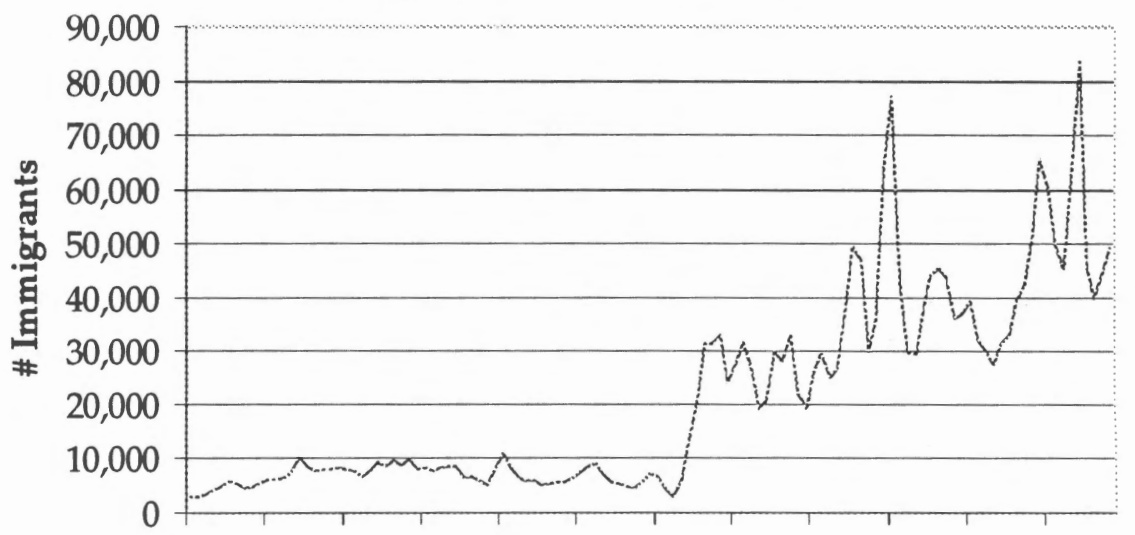

188018901900191019201930194019501960197019801990

Year

FIGURE 2

Country of Origin

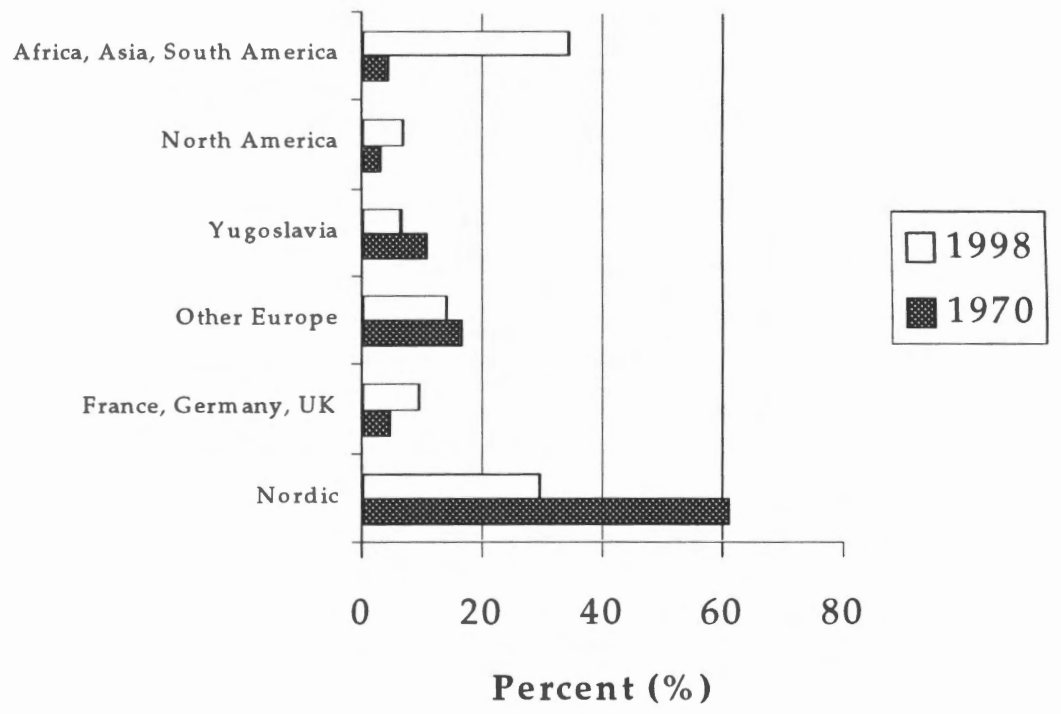

1 Throughout this paper the distinction between "foreign born" and "immigrants" will be blurred although the terms are slightly different. "Immigrants" include anyone admitted to Sweden with a resident permit and include those admitted as (1) refugees, (2) close relatives of Swedish residents, (3) those admitted for labor market reasons, (4) visiting students and scholars, (5) adopted children, (6) citizens of European Union member states, and $(7)$ return Swedish migrants. Because a certain number of "immigrants" are return migrants and because children born in Sweden to foreign-born parents are not automatically entitled to Swedish citizenship (as is the case in the U.S.), not all immigrants are foreign born. Foreign-born individuals who are at least 18 years old may elect to become Swedish citizens after a period of five years residency (two years in the case of Nordic immigrants) and therefore are technically not "immigrants" in the sense that they require resident permits to remain in Sweden. Because the records available for this study refer to "country of birth," the "immigrants" referred to in the text of this study actually correspond to the "foreign born." 
socioeconomic background (Lundborg 1991; Fischer et al. 1998; Fischer and Malmberg 1997). This paper is concerned primarily with the second issue. It examines the migration behavior of the foreign born and the demographic, socioeconomic, and cultural forces that shape it. The implications of the results for public policy, regional economic growth, and regional economic-demographic modeling are discussed.

The settlement patterns and migration behavior of immigrants are of concern to academics and policy makers for several reasons. First, governments have an interest in integrating immigrants into society. This integration (or assimilation) has been measured in a number of ways. One approach is to examine the settlement and mobility patterns of immigrants for evidence of geographical concentration or dispersion (Andersson 1996). ${ }^{2}$ Second, labor mobility is an important factor in the smooth operation of regional labor markets and achieving economic efficiency. If, however, migration flows come to be affected more by mobility impeding institutional and/or cultural influences, this situation could have a negative effect on labor market flexibility and contribute to regional economic imbalances. Therefore, it is important to study immigrant settlement and mobility decisions to determine if immigrants are motivated by the same considerations as natives. Third, governments, for reasons to be explained later, often attempt to influence the settlement choices of immigrants and their subsequent mobility decisions. However, there is considerable disagreement over whether these attempts have been successful (Borgegård, Håkansson, and Müller 1996; Rooth 1998). Finally, migration is the most important source of demographic change on the regional or local level (more than 80 percent of the change in population size and composition at the community level in Sweden is related to net migration). However, interregional economic-demographic models always assume that the foreign born are the same as natives. ${ }^{3}$ While this assumption may be needed to keep models simple, simulations vis-à-vis immigration policy questions with a relatively short reference period are likely to be less accurate.

This paper is part of a longer-term project to build a spatial-environmentaleconomic-demographic microsimulation model of Swedish society called SVERIGE, or System for Visualising Economic and Regional Influences Governing the Environment (Vencatasawmy, Holm, and Rephann 1999). It is a precursor for a study that will simulate the effects of changing immigration origins and settlement patterns on various national and regional economic-demographicenvironmental outcomes. The spatial microanalytic approach that motivates this analysis has some advantages over conventional aggregate macroeconomic econometric and computable general equilibrium models. First, it can be used to examine the distributional impacts of various policies, such as immigration, as well as their aggregate effects. Second, it can account for heterogeneity in driving

\footnotetext{
${ }^{2}$ Not everyone agrees that assimilation success can be measured by looking at residential segregation and migration behavior. For example, Ellis and Wright (1998) argue that immigrant clusters improve immigrant educational and employment opportunities and that equalization in these areas is more indicative of assimilation.

${ }^{3}$ Examples are interregional economic-demographic econometric models such as NRIES II (Isserman 1993), ECESIS (Beaumont et al. 1986), and REMI (Treyz, Rickman, and Shao 1992).
} 
forces in a way that can potentially improve results aggregated to the national level. Since there is reason to believe (see Section 2 below) that the foreign born and natives exhibit different mobility patterns, model simulation and forecasting may be strengthened by distinguishing between these two groups.

This paper is divided into several sections. The next section provides a review of literature concerning immigrant settlement choices and the internal migration behavior of immigrants afterwards. The third section describes the unique database used to make empirical estimates for the migration models here. This geographically detailed micro database allows researchers to investigate social science questions that cannot be examined easily in the United States because of data limitations and restrictions on research uses. The fourth section develops the equations used to investigate whether the foreign born differ from Swedes in their propensity to migrate and choice of destination. In addition, it describes how cultural factors are likely to influence these decisions. The fifth section reports the results of the empirical analyses. The paper concludes with a summary and conclusion.

\section{LITERATURE REVIEW}

Much has been written about the settlement patterns of immigrants in various Western, industrialized countries. Much of this literature is concerned about the housing choices of immigrants and the degree to which ethnic segregation occurs. Another strand of literature investigates the role of economic and social factors in immigrant location. Two competing influences have attracted the most attention: economic incentives or work opportunities and communities of ethnically similar individuals. One view is that economic opportunities are the most powerful attracting force during early stages of immigration but that communities of ethnically similar individuals exert a greater influence as the foreign-born population grows (O'Loughlin 1985; Clark 1996). Foreign-born clusters may attract subsequent immigrant inflows for several reasons: (1) they are indicative of networks for employment and housing information that assist new arrivals; (2) they provide various types of informal social support for immigrants in a situation of complex uncertainty; (3) they mark areas where immigrants are less likely to face discrimination and harassment; (4) they may reflect the availability of labor market opportunities in particular niches that match immigrant job skills; and (5) they may host specialized immigrant social services placed there by the government in order to minimize the costs of providing such services. The attractive force of immigrant communities may be mediated by several variables, including country of origin, language, level of education, and occupation. There is evidence that some foreign-born groups may be more attracted to clusters than others (Dunlevy 1991; Bartel 1989). Moreover, destinational characteristics having nothing to do with the size of the existing foreign-born settlement still exert a powerful force on immigrant settlement choices (Dunlevy 1991; Bartel 1989).

Public policy can influence immigrant settlement patterns and subsequent migration decisions by concentrating new arrivals in particular locales or by pro- 
viding incentives for immigrants to settle in areas they might not otherwise consider. These policies are sometimes applied to large inflows of refugees. One approach (known in Sweden as the "Whole of Sweden Strategy") is to disperse immigrants in a manner similar to native distribution patterns (Rooth 1998). Such policies are adopted for a variety of reasons, including: (1) to better utilize limited housing and infrastructure for the care of immigrants; (2) to decrease the cost of maintaining immigrants; (3) to lessen native resistance to refugees and dilute their visibility by spatially dispersing them; (4) to encourage their spatial assimilation; and (5) to disperse their labor market effects and possibly relieve regional labor shortages in peripheral areas. Rooth (1998) argues that one effect of the refugee policy in Sweden has been to induce "migration into the centers later on." Therefore, it may be revealing to distinguish refugees from other immigrants when studying immigrant migration behavior.

Much less is known about immigrant mobility after they have settled in a country. Simon (1989) writes "It is logical that new immigrants should be particularly mobile, because (unlike natives) they do not already have a stock of knowledge of persons and institutions which make it cheaper to remain in a given place than to begin anew elsewhere." In a similar vein, Fischer et al. (1998) write that "individuals who have immigrated from abroad should be at the outset more mobile than natives, as they have already lost their location-specific insider advantages and have not yet accumulated many new ones." Australian (Norman and Meikle 1983), American (Belanger and Rogers 1992; Kritz and Nogle 1994), and Canadian (Moore and Rosenberg 1995) studies appear to support this hypothesis. Fischer and Malmberg (1997) find that the foreign born in Sweden are initially more mobile than natives but that their propensity to migrate decreases with time spent in Sweden. A competing explanation for these findings is that the foreign born, who typically have less information about locational advantages within a country, may be more prone to make "locational errors," which require more frequent "corrective" or return migration at the onset.

Yet, there are equally compelling reasons to expect that the foreign born would be less mobile. The same factors that cause the foreign born to cluster in certain areas may serve to impede migration, too. Immigrant clusters may offer a variety of nonmonetary benefits that significantly erode the advantages to migrate created by economic opportunities in other regions. Second, the foreign born are less likely to be familiar with national job opportunities than are citizens who have lived their entire lives in the country, been socialized there, and developed significant networks there. Third, the foreign born may lack the language skills that are a prerequisite for entering the national labor market. Finally, the foreign born may face discrimination in labor markets (particularly in areas unaccustomed to immigrants), thereby decreasing the economic benefits of migrating. Although no empirical studies support the hypothesis that immigrants are less mobile than natives, two studies (Kritz and Nogle 1994; Moore and Rosenberg 1995) find that immigrant clusters have an impeding effect on immigrant interregional moves. In addition, Fischer and Malmberg (1997) find no differences between Finnish and 
Baltic foreign-born and native Swede migration propensities once the usual lifecycle and economic explanatory variables are introduced. That is to say, individual attributes such as age and income explain group mobility differences rather than national origins for these particular groups. As will be shown later in the paper, foreign-born residents in Sweden are generally more mobile than natives, but they are also younger, lower income, less likely to be employed, and less likely to be home owners, all of which are associated with a higher propensity to migrate.

Another question that is difficult to divorce from the issue of propensity to migrate is where foreign-born individuals migrate to when they do migrate. If they are more mobile, one possibility is that they move in order to be closer to ethnically similar individuals rather than in response to pecuniary economic incentives, such as employment and earnings opportunities. This situation might be more likely to arise in situations in which initial immigrant settlement decisions were uninformed or dictated by public policy (such as the "Whole of Sweden Strategy"). In this event, greater mobility may not signal greater assimilative potential but rather the reverse. Regional effects may be manifested in increased residential segregation, perhaps greater urban concentration, and labor markets that do not equilibrate as well. The opposite scenario is equally plausible. Immigrants may become more sensitive to economic incentives once language and cultural impediments are removed after a few years of acculturation to the host society. In addition, they may have a greater propensity to move to places with more employment opportunities if their unemployment risk is higher. It might also be argued that, if foreign-born residents have looser attachments to place (or "insider advantages"), they may be more likely to respond to pecuniary incentives because "return migration" (i.e., migration to place of birth) cannot influence migration patterns. Unfortunately, there appears to be little empirical literature available that can shed light on this migration issue.

\section{DATA}

The data used for the empirical work in this paper are drawn from a unique, longitudinal, geographically descriptive micro database called TOPSWING (TOtal Population of SWeden INdividual and Geographical database), obtained from Statistics Sweden and housed at the Spatial Modelling Centre in Kiruna, Sweden. The database contains detailed demographic and socioeconomic information about every resident in Sweden during the period 1985-1995 derived from quinquennial censuses and tax and social insurance records. Some of the more relevant items available for this study are variables representing age, sex, marital status, number and age of dependents, educational level, country of birth, length of residency in Sweden, income, and employment status. In addition, the database identifies the location of workplaces and residences with geographical coordinates measured at a level of accuracy of 100 square meters. This resolution makes it possible to aggregate individuals into various user-specified regional boundaries for analysis and to visualize spatial outcomes with Geographical Informa- 
tion Systems. For the purposes of the present study, however, only migration between labor market regions is modeled. Sweden is divided into 108 separate labor market areas (also known as "LA regions") according to 1990 definitions developed by Statistics Sweden and the Swedish Department of Finance (Finansdepartementet 1995). The labor market boundaries (see Figure 3) are selected in a way that maximizes intraregional commuting flows and minimizes interregional flows. Since the main factor in daily activity is commuting distance, labor market areas are the most appropriate geographical units for interregional migration research.

FIGURE 3

Labor Market Regions in Sweden

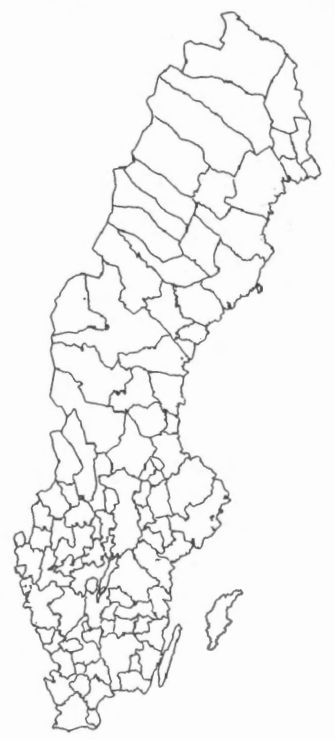

TOPSWING has information on approximately nine million Swedish residents. In the subsequent analysis, two separate data sets were extracted from this database to study. The first consisted of a 5 percent sample of Swedish families, drawn from the database in order to make microdata empirical work manageable. This sample was created by utilizing a systematic random sampling method. The sample contains 458,854 individuals who were resident in Sweden in 1990, including 9,862 who moved between labor markets during the year. It is worth noting that, whereas the foreign born make up 13.6 percent of the sample, 18.4 percent of the movers are foreign born. The sources of this discrepancy will be investigated in the remaining sections. The second data set consisted of aggregate labor market migration flows that were computed using information on all nine million residents from the database. Also, labor market indicators for both the microdata and aggregate labor market migration flow studies described below were computed with information obtained from the full database rather than the sample.

For the subsequent analysis, unless indicated otherwise in the tables, all values are measured in 1990 and migration occurs during 1990. Moreover, individuals between the ages of 25 and 65 are used as the units of analysis (reduc- 
ing the sample size to 238,994$)$. These age cutoffs were chosen because the resulting population is more likely to be influenced by labor market conditions than minors, college-age migrants, and retirees. Individuals are used as observations rather than household heads, although there are arguments in favor of each (Flowerdew and Boyle 1995).

\section{EXPLAINING IMMIGRANT MOBILITY}

\section{Decomposing the Migration Decision}

Geographers have argued that migration decisions are highly complex because individuals are typically faced with the problem of processing information concerning a large number of potential alternatives (Stillwell 1991). Indeed, there is some evidence that suggests that individuals have a limited capacity for processing such information (Simon 1969; Lindsay and Norman 1972; Newell and Simon 1972; Norman and Bubrow 1975). Because of these human limitations and in order to represent choices in a manageable way, it has been proposed that migration decisions be modeled in a nested, hierarchical manner (Holm and Malmberg 1997; Moore and Rosenberg 1995). A similar hierarchical approach has been recommended to represent industrial location search by firms (Walker and Calzonetti 1990).

One way to model the interregional migration decision, suggested in Holm and Malmberg (1997), is to split it into three separate decisions. First, an individual decides whether or not he or she wants to migrate. This choice is likely to be influenced by a variety of life-cycle and economic factors. Once the individual has made that decision, he or she must determine which region offers the best migration possibilities based on destination opportunities and origin characteristics. Finally, the individual chooses a locality within the region to occupy. For this paper, only the first two decisions will be investigated.

\section{The Decision to Migrate}

The first decision can be estimated using logit regression, where the independent variables consist of individual demographic and socioeconomic characteristics that are likely to influence a person's desire to migrate. The value of the dependent variable is equal to one if an individual moved between labor markets in 1990 and zero otherwise. There is a large literature regarding the variables that influence migration decisions (Greenwood 1975). These attributes include individual and household characteristics such as age, sex, household income, home ownership, previous number of moves, level of education, number of children, marital status, employment status, and duration of stay in present location. Table 1 shows the variables selected from TOPSWING to be used in the empirical analysis.

Demographic factors are the most conspicuous determinants of propensity to migrate. Migration propensities are greatest during young adulthood, when individuals make the decision to go to university or enter the labor force, and diminish with age (indicated in the model by AGE). Economic theory predicts this 


\title{
TABLE 1
}

Determinants of Decision to Migrate

\section{Dependent Variable}

MIGRATE Bivariate variable indicating migration between labor markets.

Demographics

$\begin{array}{ll}\text { AGE } & \text { Age in years. } \\ \text { AGESQ } & \text { Age in years squared. } \\ \text { SEX } & \text { Dummy variable indicating individual is female. }\end{array}$

Family

NCHILD Number of children in the household.

MARRIED Dummy variable indicating individual is married.

DIVSEP Dummy variable indicating individual is divorced, separated, or widowed.

\section{Mobility \\ DURATION Length of residency in originating labor market (in months). \\ NMOVE Number of moves during period 1985-89. \\ HOME Dummy variable indicating home ownership.}

\author{
Employment and Earnings \\ FAMEARN Annual earnings of individual and household partner $(1,000$ s of SEK). \\ WORK Dummy variable for employed. \\ $\mathrm{HIGH} \quad$ Dummy variable indicating high school graduate. \\ COLLEGE Dummy variable indicating college graduate.
}

Immigration

FLAND

FLAND1

FLAND2

FLAND3

FLAND4

PFLAND1

PFLAND2

PFLAND3

PFLAND4

PFLAND5

MFLAND

MFLAND1

MFLAND3

MFLAND4

MFLAND5

YEARIMIG

Regional

UNEMP

EARN
FLAND5

MFLAND2

Dummy variable indicating foreign born.

Dummy variable indicating Nordic origin.

Dummy variable indicating Western European, North American, or Oceanic origin.

Dummy variable indicating Southern or Eastern European origin.

Dummy variable indicating Latin American or Balkan origin.

Dummy variable indicating Asian or African origin.

Proportion of labor market population from Nordic (excluding Sweden)

countries.

Proportion of labor market population from Western Europe, North America, or Oceania.

Proportion of labor market population from Southern or Eastern Europe.

Proportion of labor market population from Latin America or Balkans.

Proportion of labor market population from Asia or Africa.

FLAND $\times$ PFLAND

FLAND1 $\times$ PFLAND1

FLAND2 $\times$ PFLAND2

FLAND3 $\times$ PFLAND3

FLAND $4 \times$ PFLAND 4

FLAND $5 \times$ PFLAND5

Years resided in Sweden.

result because younger people typically have the most to gain from migration, since they are both likely to have relatively small costs of relocating (both out-ofpocket and psychic) and have many active employment years to realize the benefits of migration (Ehrenberg and Smith 1991). However, a slight increase in the tendency to migrate can be expected for those entering retirement age (captured 
in the model by including a squared age term, AGESQ) as the workplace ceases to bind them to a particular region. Gender (represented in the model by SEX, a dummy variable indicating female gender) is typically not an important personal characteristic that distinguishes migrants from nonmigrants in empirical research. However, there are reasons to expect some relationship, both positive and negative. For instance, wage discrimination against females, particularly if concentrated in higher-earning occupational fields, would result in lower returns to female migration and a lesser propensity to migrate. On the other hand, if as has been observed in labor force decision studies, women are more sensitive to income and wages than men (Killingsworth and Heckman 1986), women should be more responsive to interregional differences in wages as well and show a greater propensity to migrate.

Stronger family commitments, such as being married or having children, generally decrease interregional mobility. When individuals are married (represented in the model by MARRIED, which is a dummy variable indicating legal marriage rather than common law marriage or cohabitation), the mobility decision is affected by the increased costs of movement and the probable loss of comparable spousal income in the new location. This mobility-impeding effect of marriage may be more severe for females since males are generally the higher wage earner in families. Divorcees (indicated by a dummy variable, DIVSEP, which identifies individuals who are divorced or separated) do not face the same constraints, and may in fact have the desire to migrate in order to correct for suboptimal location decisions that were imposed during marriage. Children also have been found to decrease individual mobility, but the ages of the children are important. Generally, school-age children are more of an impediment than preschoolers are since the psychic costs of relocation are likely to be much higher. In addition, larger families are more costly to move than smaller families. The number of children present in the household (represented by NCHILD) is used here to capture both of these effects. Since larger families will be more likely to have older children as well, this will tend to reinforce its mobility-inhibiting effects.

Some variables are indicators for one's "attachment to place," "insider advantages," or the stock of social capital accumulated in certain locales. Individuals who move frequently (indicated in the model by NMOVE, the number of moves during the period 1985-89) or have resided at a particular location for only a short time (represented by DURATION, the number of consecutive months resided in the labor market) are less likely to have established intimacy with residents and formed the kinds of social, professional, and civic ties that would result in substantial psychic costs if they moved (Fischer and Malmberg 1997). Home ownership (indicated by a dummy variable, HOME, which identifies homeowners) is another indicator of local rootedness. Those who do not purchase a home may be revealing their preference to remain mobile and should have substantially lower moving costs because they do not need to sell a home. 
Basic economics is the motivating factor in most interregional migration decisions. Those with secure, high household incomes (represented by FAMEARN, which measures the income of noncohabitating individuals or the combined incomes of cohabitating male and female household heads) are less likely to migrate. ${ }^{4}$ Low wage earners and the unemployed (indicated by a dummy variable, WORK, which identifies employed individuals) are more likely to migrate. This relationship may be clouded to some extent. Individuals in lower income classes may also differ substantially in their future orientation, preferring present to future consumption. If this is evident, substantial differences in interregional opportunities may be necessary to motivate job search and relocation. Coupled with the relatively generous social support system in Sweden, these effects may counter somewhat the relationship between earnings and migration. College-educated individuals (represented by COLLEGE, a dummy variable indicating whether an individual graduated from college or university) may have a greater propensity to migrate because they are more likely to be integrated into national labor markets.

Two regional variables that describe economic conditions in the origin labor market are included. These are the "unemployment rate" (indicated by UNEMP, the proportion of labor market residents between 16 and 65 years of age who are not employed) and average earnings (EARN, labor market average annual earnings for those who are employed). Each is expected to capture push influences in migration decisions. Although a particular individual may have secure and rewarding employment, lagging regional conditions may signal greater risk and uncertainty about future employment possibilities and fewer opportunities for advancement. Several other regional indicators are used to reflect regional immigrant networks, but they are discussed below.

\section{Choice of Destination}

The choice of destination will be assumed to depend on the attributes of the origin and destination labor markets. The regression equation adopted here is based on a modified gravity model of migration flows as described in Isserman et al. (1985). It models migration flows from labor market $i$ to $j$ as a function of origin and destination populations, distance, and various economic variables. Each of the variables included, expressed in terms of natural logarithms, is defined in Table 2. Expectations are that the logarithms of the populations of the origin (LAPOP) and destination (LBPOP) labor markets are directly related to labor market migration flows, while the logarithm of distance between the geographical centers of the labor market population (LDISTANCE) is inversely related. Also, the logarithm of average labor market earnings in the destination region (LBEARN) is expected to be positively associated with migration flows while the logarithm of the labor market "unemployment rate" (LBUNEMP) is expected to have a negative association. In addition, because this study is interested in the

${ }^{4}$ When both partners work, migration may result in loss of income for one of the partners. This specification takes into account the argument that the availability of income opportunities for both partners plays a role in the location decisions of an increasingly large number of two-earner households. 
attractive/repulsive effects of immigrant communities on migration flows, measures of immigrant networks are included (the logarithms of the proportion of labor market residents who are foreign born in the destination and origin labor markets, LBFLAND and LAFLAND).

TABLE 2

Determinants of Labor Market Migration Flows

\begin{tabular}{ll}
\hline LBPOP & $\begin{array}{l}\text { Log of population in destination labor market region } \\
\text { LAPOP }\end{array}$ \\
LDISTANCE & $\begin{array}{l}\text { Log of population in origin labor market region } \\
\text { market regions }\end{array}$ \\
LBEARN & $\begin{array}{l}\text { Log of average annual earnings (100s of SEK) for residents between 16-65 years } \\
\text { of age in destination labor market regions } \\
\text { Log of average annual earnings (100s of SEK) for residents between 16-65 years } \\
\text { of age in origin labor market regions } \\
\text { LAEARN }\end{array}$ \\
LBUNEMP & $\begin{array}{l}\text { Log of proportion of residents between 16 and } 65 \text { years of age not employed in } \\
\text { destination labor market regions }\end{array}$ \\
LAUNEMP & $\begin{array}{l}\text { Log of proportion of residents between 16 and } 65 \text { years of age not employed in } \\
\text { origin labor market regions }\end{array}$ \\
LBFLAND & $\begin{array}{l}\text { Log of proportion of residents in destination labor market region that is foreign } \\
\text { born } \\
\text { Log of proportion of residents in origin labor market region that is foreign born }\end{array}$ \\
LAFLAND &
\end{tabular}

\section{Differences in Immigrant Migration Behavior}

Recall that a key question is whether the migration behavior of the foreign born differs from that of natives. Because migration is a complex spatial decision, it is useful to further subdivide the question into two subquestions corresponding to the first two decisions described earlier. Do the foreign born have a greater or lesser propensity to migrate, once demographic and socioeconomic attributes affecting the migration decision are controlled for? Do these demographic and socioeconomic determinants play as important roles in foreign-born mobility behavior as they do for natives? Furthermore, once the migration decision has been made, do the foreign born respond to the same location incentives? Do they, for instance, tend to move where there are greater economic opportunities or to cluster in areas with larger foreign-born populations?

Dividing Swedish residents into foreign born and natives may suffice for an initial analysis. However, the foreign born are a fairly heterogeneous group. Some groups encounter few cultural or language barriers in Sweden and might be expected to cope easily with conditions in their adopted country. Therefore, they may be expected to exhibit mobility behavior that resembles that of native Swedes. Although Sweden has a fairly generous and elaborate system for educating and assimilating immigrants and strong antidiscrimination laws, some may still face substantial problems because of language barriers and cultural differences.

One way to measure the level of anxiety and discomfort that immigrants are likely to encounter is to ask the natives themselves. Lange (1991) constructed a "cultural distance" index based on a national survey of Swedish attitudes towards different foreign-born groups (see Figure 4). It shows that Nordic immigrants (who share the same religion and, with the exception of the Finns, a similar 
language) are regarded as being the most similar to themselves. Western Europeans and North Americans can be aggregated into the next category followed by Southern and Central European nationals. Latin Americans and immigrants from the Balkan states of Yugoslavia and Greece are more dissimilar. The most culturally distant are immigrants from Asia and Africa.

FIGURE 4

Cultural Distance

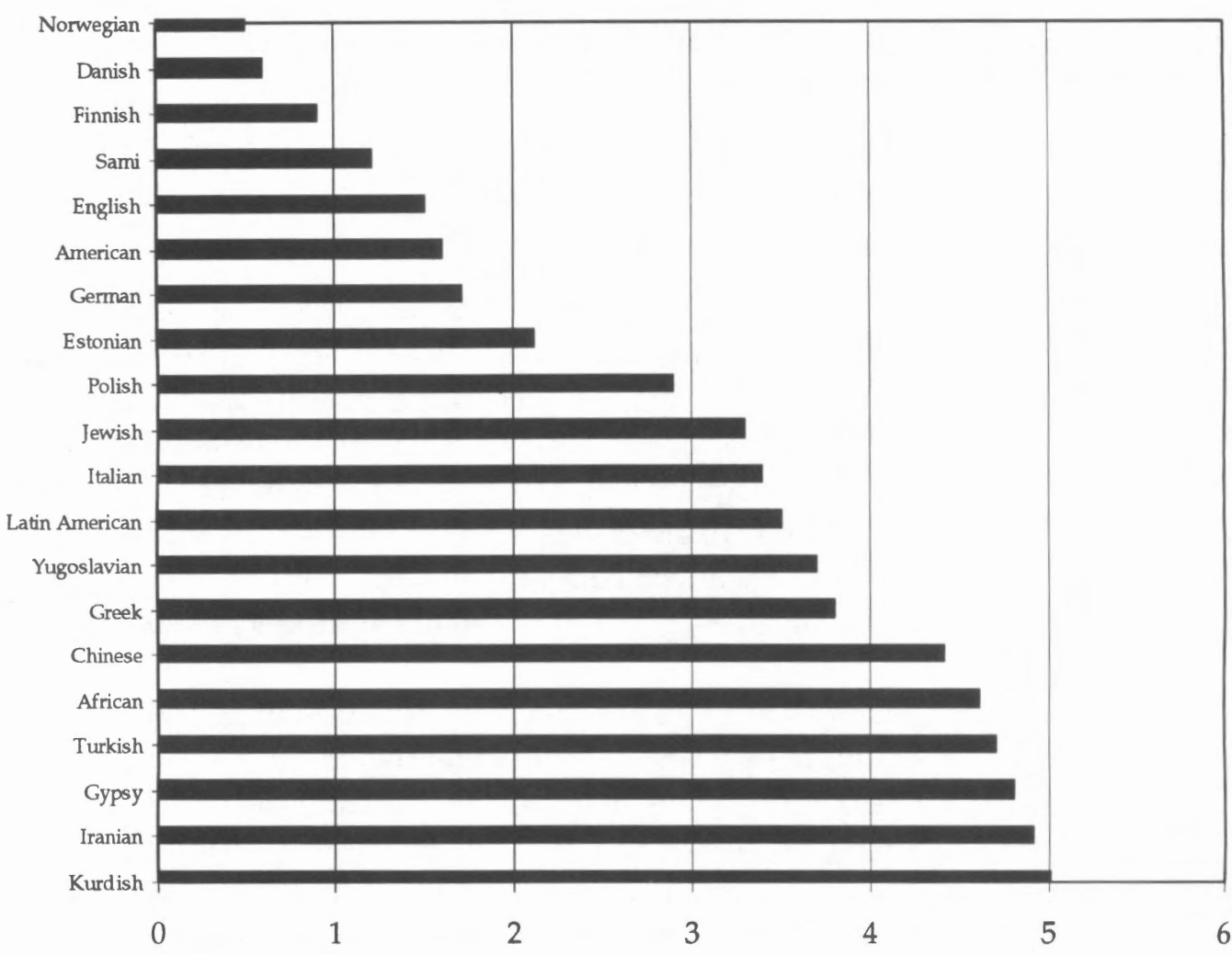

The issue to investigate here is whether differences in the mobility behavior of the foreign born based on this classification can be observed. One might anticipate the effects of being foreign born to be inconsequential for Nordic immigrants. On the other hand, the effects may be particularly pronounced for Asian and African immigrants, who are viewed as being the most different. An attempt was made to create homogenous foreign-born typologies based on Lange's index using the TOPSWING data. Table 3 lists the principal countries included in each of the categories. This typology was used in creating identifiers for each individual in the database. The variable FLAND indicates whether an individual is foreign born or not; FLAND1 identifies Nordic foreign born, FLAND2 indicates Northwestern Europe, North American, and Oceanic, foreign born, and so forth. 


\section{TABLE 3}

Immigrant Origin Categories

Nordic: Norway, Denmark, Iceland, Finland.

Northwestern Europe, North America, and Oceania: Germany, Great Britain, Ireland, Other Europe, America, Canada, Oceania.

Southern and Eastern Europe: Baltic States, Greece, Italy, Spain, Portugal, Albania, Romania, Czechoslovakia, Poland, Hungary, Former Soviet Union, Bulgaria.

Latin America and the Balkans: Yugoslavia, Bosnia-Herzegovina, Central America, Chile, South America.

Asia and Africa: North Africa, Sub-Saharan Africa, Ethiopia, Eritrea, Somalia, Sudan, Iran, Iraq, Turkey.

\section{RESULTS}

The first section in Table 4 shows the results of a logit regression for the decision to migrate between labor markets using socioeconomic and demographic explanatory variables described in Section 4 . The table reports maximum likelihood parameter estimates (b slope), corresponding p-values, ${ }^{5}$ marginal probability values (i.e., marginal $\beta$ ), ${ }^{6}$ the chi-square test statistic, ${ }^{7}$ and Somers' ${ }^{\prime} .^{8}$ Only results statistically significant at the $\alpha=0.10$ are discussed. Since the results for this regression form a benchmark for subsequent comparisons and because the coefficient signs are noteworthy in themselves, some of the major findings are summarized here.

First, the propensity to migrate is a quadratic function of age (AGE). Family obligations, as expected, have a negative effect on the likelihood of migration; having children (NCHILD) and being married (MARRIED) decrease the likelihood while being divorced or separated (DIVSEP) increases it. An individual is less likely to migrate if he or she has a greater attachment to the area as measured by duration of stay at the present location (DURATION) and home ownership (HOME). Individuals who already have a degree of economic security as measured by higher family earnings (FAMEARN) and being employed (WORK) are less likely to move. Higher education achievement (COLLEGE), on the other hand, is associated with greater mobility. Finally, a healthier local economy (EARN) is associated with a lower propensity to migrate. Besides FLAND, only three of the socioeconomic and demographic variables are not statistically significant: SEX, NMOVE, and UNEMP. The argument in favor of including gender was a tenuous one, so statistical insignificance is not terribly surprising. NMOVE is moderately correlated $(\rho=-0.54)$ with DURATION, the second mobility indicator

${ }^{5}$ These p-values are based on the Wald chi-square statistic, which is computed by squaring the ratio of the parameter estimate divided by its standard error estimate. They provide a test for the individual effects of each of the independent variables in the model.

${ }^{6}$ The marginal $\beta$ shows how a change in one independent variable affects the overall probability conditional on all other independent variables being evaluated at their mean values.

${ }^{7}$ These p-values are based on the $-2 \log \mathrm{L}$ statistic, which has a chi-square distribution under the null hypothesis. They are used to test the joint effect of the independent variables included in the model.

${ }^{8}$ Somers' D is a rank correlation measure between probabilities predicted by the estimated equations and observed responses. 
used in the regression. UNEMP is a somewhat unreliable measure of the "unemployment rate" as constructed because it actually measures those not employed (i.e., both unemployed individuals and those out of the labor force). In general, however, the results conform to expectations.

\section{TABLE 4}

Results for Decision to Migrate

\begin{tabular}{|c|c|c|c|c|c|c|}
\hline & b slope & $\begin{array}{c}(1) \\
\operatorname{Pr}>\chi^{2}\end{array}$ & Marginal $\beta$ & b slope & $\begin{array}{c}(2) \\
\operatorname{Pr}>\chi^{2}\end{array}$ & Marginal $\beta$ \\
\hline Constant & $5.8100^{\circ}$ & 0.0001 & 0.06753 & 4.6364 & 0.0001 & 0.05533 \\
\hline AGE & -0.0446 & 0.0001 & -0.00052 & -0.0428 & 0.0003 & -0.00051 \\
\hline AGESQ & 0.00036 & 0.0088 & -0.00000 & 0.0004 & 0.0125 & 0.00000 \\
\hline SEX & -0.0179 & 0.5528 & -0.00021 & -0.0174 & 0.5639 & -0.00021 \\
\hline NCHILD & -0.1729 & 0.0001 & -0.00201 & -0.1718 & 0.0001 & -0.00205 \\
\hline MARRIED & -0.2208 & 0.0001 & -0.00257 & -0.2243 & 0.0001 & -0.00268 \\
\hline DIVSEP & 0.1681 & 0.0021 & 0.00195 & 0.1726 & 0.0016 & 0.00206 \\
\hline DURATION & -0.0362 & 0.0001 & -0.00042 & -0.0360 & 0.0001 & -0.00043 \\
\hline NMOVE & 0.0085 & 0.4577 & 0.00009 & 0.0114 & 0.3176 & 0.00014 \\
\hline HOME & -0.2277 & 0.0001 & -0.00265 & -0.2186 & 0.0001 & -0.00261 \\
\hline FAMEARN & -0.0004 & 0.0019 & -0.00000 & -0.0004 & 0.0013 & -0.00000 \\
\hline WORK & -0.5237 & 0.0001 & -0.00609 & -0.5172 & 0.0001 & -0.00617 \\
\hline $\mathrm{HIGH}$ & 0.2355 & 0.0001 & 0.00274 & 0.2314 & 0.0001 & 0.00276 \\
\hline COLLEGE & 0.7583 & 0.0001 & 0.00881 & 0.7501 & 0.0001 & 0.00895 \\
\hline FLAND & -0.0192 & 0.7490 & -0.00022 & 0.9188 & 0.0001 & 0.01096 \\
\hline MFLAND & & & & -9.7549 & 0.0001 & -0.11641 \\
\hline YEARIMIG & -0.0245 & 0.0001 & -0.00028 & -0.0246 & 0.0001 & -0.00029 \\
\hline UNEMP & -0.7844 & 0.3595 & -0.00912 & 0.6953 & 0.4422 & 0.00890 \\
\hline EARN & -0.0402 & 0.0001 & -0.00047 & -0.0331 & 0.0001 & -0.00039 \\
\hline $\begin{array}{l}\text { Number of } \\
\text { Observations }\end{array}$ & 238,994 & & & 238,994 & & \\
\hline MIGRATE & 0.0208 & & & 0.0208 & & \\
\hline Chi Square (d.f) & $7198.50(17)$ & 0.0001 & & 7304.07 (18) & 0.0001 & \\
\hline Somers' D & 0.629 & & & 0.633 & & \\
\hline
\end{tabular}

The results suggest that there is no difference between the foreign born (FLAND) and natives initially, but they become more dissimilar (i.e., less mobile) with the passage of time (YEARIMIG). Based on this analysis, one might conclude that the foreign born migrate in greater proportions because they differ from natives with respect to demographic and socioeconomic characteristics known to affect the propensity to migrate. Table 5 shows that the foreign born within the 2565 age group tend to be younger, are less likely to be employed, are more likely to be divorced, are much less likely to own a home, and have resided in the labor market region for a shorter period of time. However, this conclusion would be premature because the regression fails to take into consideration two factors that may be important in migration choices. First, the size of the foreign-born community may have some bearing on the migration decision (Kritz and Nogle 1994; 


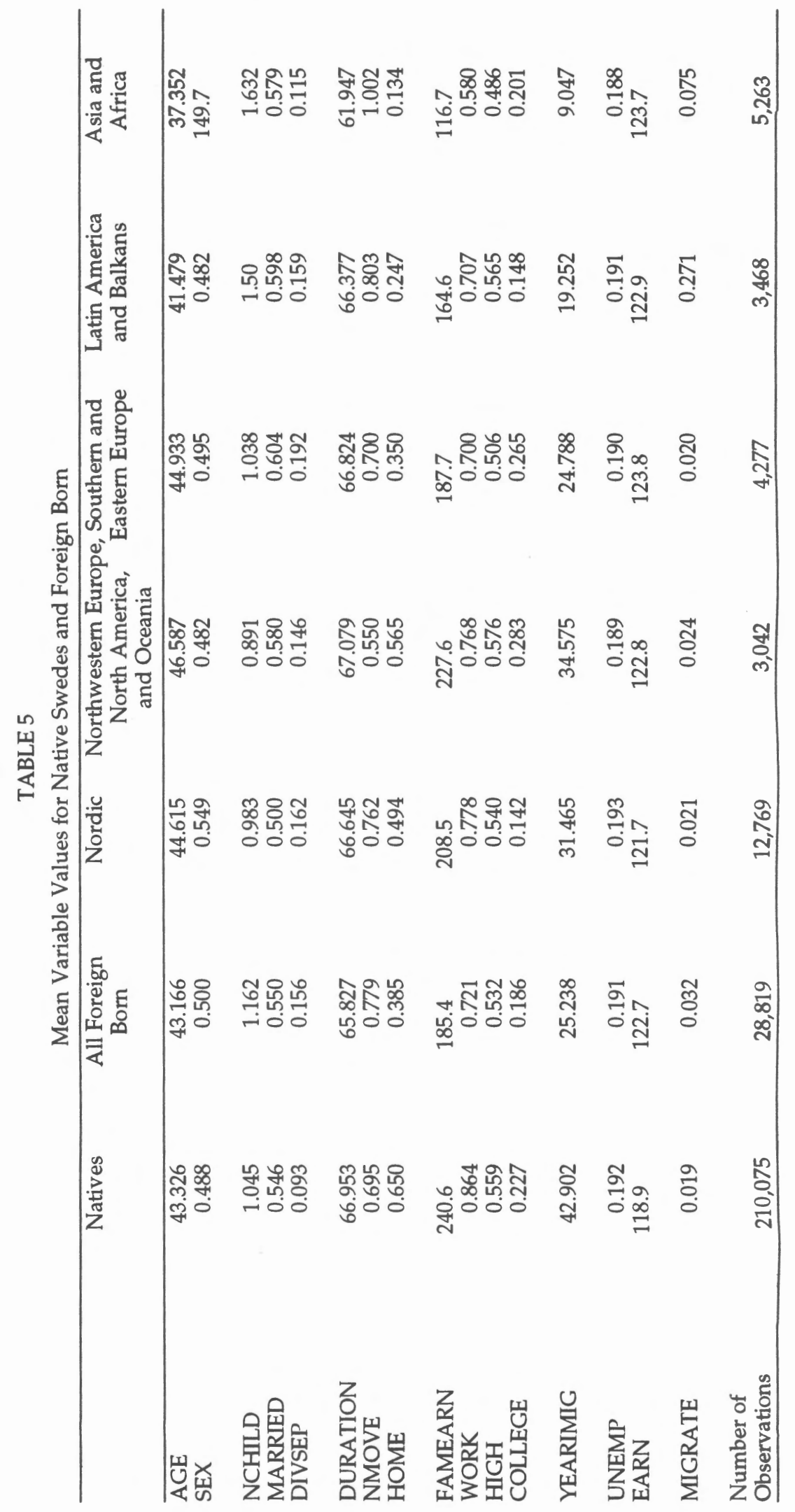


Moore and Rosenberg 1995). Immigrants may accrue certain "insider advantages" and may be reluctant to sacrifice these ties without corresponding larger rewards. Second, immigrants may differ substantially in their migration behavior depending on their national origin and the obstacles they are likely to encounter in adapting to new environments.

TABLE 6

Results for Decision to Migrate with Foreign-Born Origin

\begin{tabular}{|c|c|c|c|c|c|c|}
\hline & b slope & $\begin{array}{c}(1) \\
\operatorname{Pr}>\chi^{2}\end{array}$ & Marginal $\beta$ & b slope & $\begin{array}{c}(2) \\
\operatorname{Pr}>\chi^{2}\end{array}$ & Marginal $\beta$ \\
\hline Constant & 5.5854 & 0.0001 & 0.06566 & 4.5901 & 0.0001 & 0.05409 \\
\hline AGE & -0.0437 & 0.0002 & -0.00051 & -0.0430 & 0.0003 & -0.00051 \\
\hline AGESQ & 0.0003 & 0.0130 & 0.00000 & 0.0003 & 0.0159 & 0.00000 \\
\hline SEX & -0.0057 & 0.8511 & -0.00006 & -0.0043 & 0.8860 & -0.00005 \\
\hline NCHILD & -0.1778 & 0.0001 & -0.00209 & -0.1777 & 0.0001 & -0.00209 \\
\hline MARRIED & -0.2409 & 0.0001 & -0.00283 & -0.2420 & 0.0001 & -0.00285 \\
\hline DIVSEP & 0.1789 & 0.0011 & 0.00210 & 0.1855 & 0.0007 & 0.00219 \\
\hline DURATION & -0.0360 & 0.0001 & -0.00042 & -0.0357 & 0.0001 & -0.00042 \\
\hline NMOVE & 0.0115 & 0.3145 & 0.00014 & 0.0177 & 0.1212 & 0.00021 \\
\hline HOME & -0.2104 & 0.0001 & -0.00247 & -0.1924 & 0.0001 & -0.00227 \\
\hline FAMEARN & -0.0003 & 0.0105 & -0.00000 & -0.0004 & 0.0064 & -0.00000 \\
\hline WORK & -0.5156 & 0.0001 & -0.00606 & -0.5088 & 0.0001 & -0.00599 \\
\hline $\mathrm{HIGH}$ & 0.2496 & 0.0001 & 0.00293 & 0.2540 & 0.0001 & 0.00299 \\
\hline COLLEGE & 0.7714 & 0.0001 & 0.00907 & 0.7761 & 0.0001 & 0.00914 \\
\hline FLAND1 & -0.1168 & 0.1197 & -0.00137 & -0.1721 & 0.0833 & -0.00203 \\
\hline FLAND2 & -0.00964 & 0.9409 & -0.00011 & 1.2567 & 0.0001 & 0.01481 \\
\hline FLAND3 & -0.4008 & 0.0014 & -0.00471 & 0.7742 & 0.0015 & 0.00912 \\
\hline FLAND4 & -0.1081 & 0.3746 & -0.00127 & 1.1354 & 0.0001 & 0.01338 \\
\hline FLAND5 & 0.3980 & 0.0001 & 0.00468 & 2.4403 & 0.0001 & 0.02876 \\
\hline MFLAND1 & & & & 1.1033 & 0.3935 & 0.01300 \\
\hline MFLAND2 & & & & -125.7 & 0.0001 & -1.48121 \\
\hline MFLAND3 & & & & -68.8730 & 0.0001 & -0.81158 \\
\hline MFLAND4 & & & & -96.4574 & 0.0001 & -1.13662 \\
\hline MFLAND5 & & & & -96.0396 & 0.0001 & -1.13170 \\
\hline YEARIMIG & -0.0225 & 0.0001 & -0.00026 & -0.0215 & 0.0001 & -0.00025 \\
\hline UNEMP & -0.5424 & 0.5285 & -0.00638 & -0.6203 & 0.5003 & -0.00730 \\
\hline EARN & -0.0398 & 0.0001 & -0.00047 & -0.0320 & 0.0001 & -0.00037 \\
\hline $\begin{array}{l}\text { Number of } \\
\text { Observations }\end{array}$ & 238,994 & & & 238,994 & & \\
\hline MIGRATE & 0.0208 & & & 0.0208 & & \\
\hline Chi Square (d.f) & $7258.71(21)$ & 0.0001 & & $7516.92(21)$ & 0.0001 & \\
\hline Somers' D & 0.631 & & & 0.640 & & \\
\hline
\end{tabular}

The second section of Table 4 and both sections of Table 6 show that the results are very sensitive to these specification issues. Section (2) of Table 4 shows that once account is taken of the size of the origin foreign-born community, by using the interaction term MFLAND (= FLAND $\times$ PFLAND, where PFLAND 
represents the proportion of the labor market population that is foreign born), immigrants are more likely to migrate. Immigrants are less likely to leave regions with large foreign-born communities. Section (1) of Table 6 shows that the propensity to migrate is sensitive to national origin. Most foreign-born categories are not noticeably different from natives (the default category). Residents who originate from Southern and Eastern Europe (FLAND3) are actually less likely to migrate. Only residents from Asian and African countries (FLAND5) show a greater propensity to migrate. However, once the relative size of each foreign-born community is controlled for with interaction terms (MFLAND1-MFLAND5), most of the groups appear to be more mobile. Only residents from Nordic countries are less mobile.

Table 7 addresses the issue of whether there are any systematic differences in the sensitivity of groups to the socioeconomic and demographic variables that influence migration decisions. Results show that age is generally not a statistically significant factor in migration decisions. Gender is statistically significant in two instances. Female residents from Northwestern Europe and North America and Asia and Africa are less likely to migrate than males. The latter result might have some connection with the fact that many of these immigrants are drawn from predominantly Islamic countries in which females are expected to play more traditional roles. With the exception of Nordic and Asia and Africa categories, family variables, such as the number of children in the household, are not important in migration decisions. In addition, education is significant only for the most culturally similar categories (Nordic countries and Northwestern Europe and North America). Finally, the relative size of the foreign-born population is associated with a lower propensity to migrate, especially for the more culturally distinct categories (i.e., Latin America and the Balkans and Asia and Africa).

Table 8 reports the results of a log-linear model of labor market migration flows. Only two regressions are performed because subdividing foreign-born residents into culturally similar groups resulted in interregional migration flows that were too small to analyze. The first section shows the results of a log-linear regression of labor market migration flows for natives. The second section shows the same for the foreign born. Results for each regression are consistent with the gravity model. The logs of origin and destination populations (LAPOP and LBPOP) as well as distance (LDISTANCE) have the expected coefficient signs. In addition, the log of destination average earnings (LBEARN) has an attracting effect while the log of the origin "unemployment rate" (LAUNEMP) is repulsing. The signs on the remaining economic variables (LAEARN, log of origin earnings, and LBUNEMP, log of destination unemployment rate) are not consistent with expectations. Each should have a negative sign, implying that higher destination unemployment rates inhibit migration flows there and higher origin average earnings reduce out-migration, but the results show each is positive. These counterintuitive findings are not uncommon in the migration literature (Isserman et al. 1985). Finally, the only substantial difference between the determinants of native and immigrant flows is the role of the foreign-born community size in the origin and 


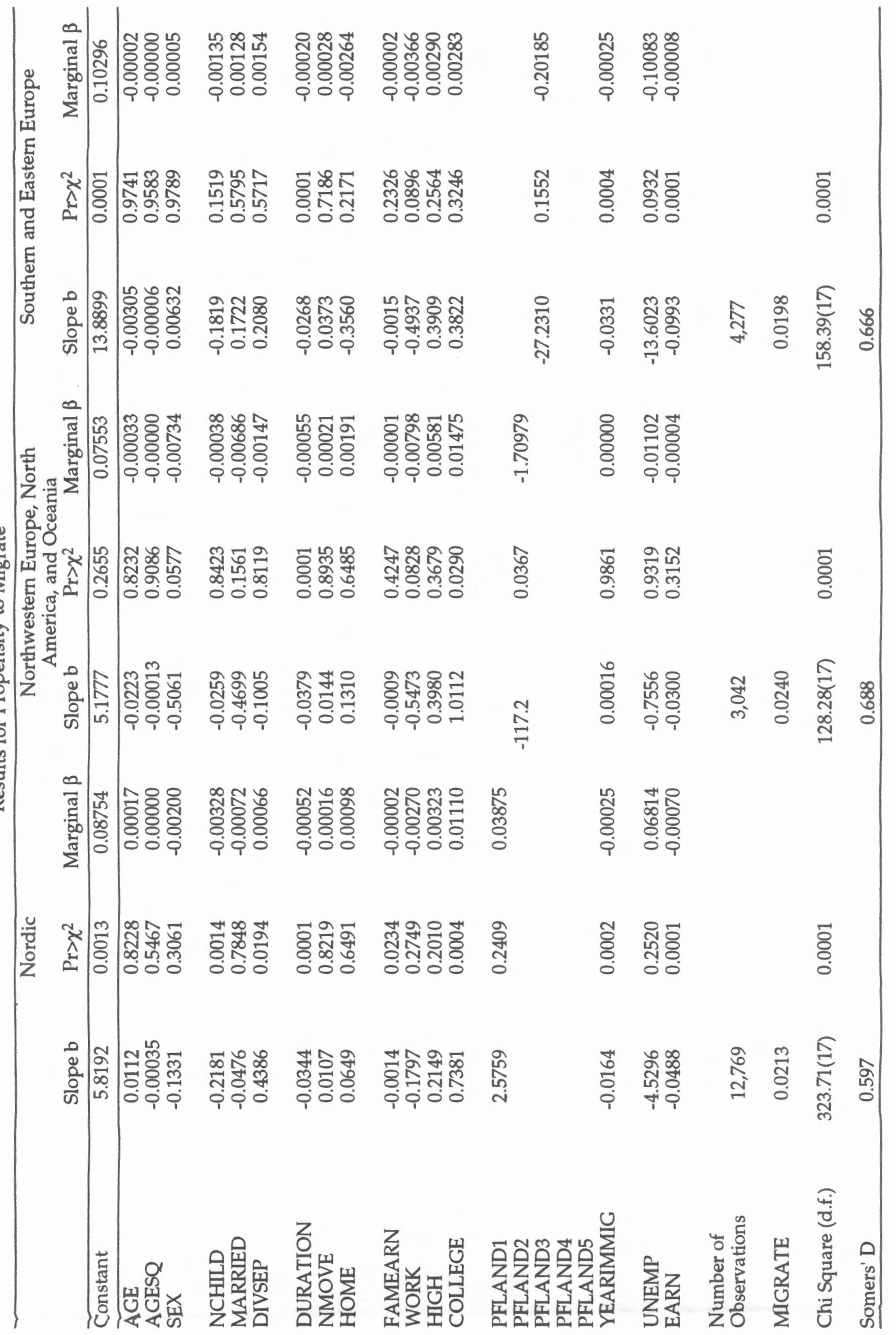




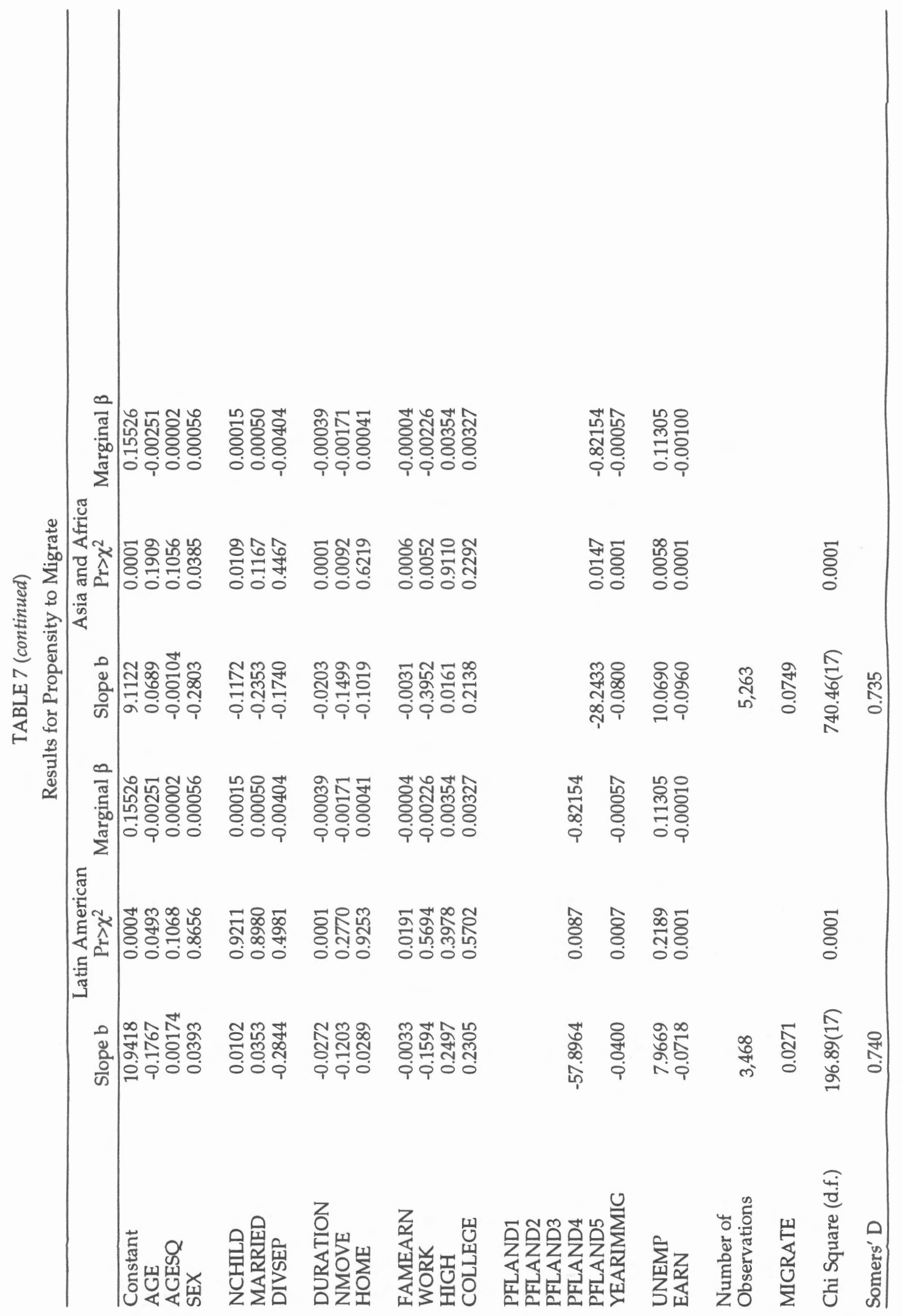


destination labor markets. The logs of the proportions of foreign-born residents in the destination and origin labor markets (LBFLAND and LAFLAND) are statistically significant in each equation. Foreign-born residents are more likely to flow from regions with relatively larger foreign-born populations to other regions with larger foreign-born populations, while natives are less likely to flow from and to such regions.

\section{TABLE 8}

Results for Labor Market Migration Flows

\begin{tabular}{lcccc}
\hline & $\begin{array}{c}\text { Parameter } \\
\text { Estimate }\end{array}$ & Pr $>|\mathrm{t}|$ & $\begin{array}{c}\text { Foreign Born } \\
\text { Parameter } \\
\text { Estimate }\end{array}$ & $\operatorname{Pr}>|\mathrm{t}|$ \\
\hline Constant & -23.3208 & 0.0001 & -6.1988 & 0.3115 \\
LAPOP & 0.2297 & 0.0001 & 0.0542 & 0.0477 \\
LBPOP & 0.2427 & 0.0001 & 0.1126 & 0.0001 \\
LDISTANCE & -0.3537 & 0.0001 & -0.1140 & 0.0001 \\
LAEARN & 2.4909 & 0.0001 & 0.4173 & 0.5185 \\
LBEARN & 0.7357 & 0.1854 & 0.5446 & 0.4318 \\
LAUNEMP & 0.8775 & 0.0001 & 0.1498 & 0.4934 \\
LBUNEMP & 0.2950 & 0.1093 & 0.2243 & 0.3097 \\
LAFLAND & -0.0960 & 0.0443 & 0.1630 & 0.0047 \\
LBFLAND & -0.0759 & 0.0986 & 0.1079 & 0.0618 \\
Number of Observations & 1,344 & & & \\
R & 0.367 & & 525 & \\
F-statistic & 85.99 & 0.0001 & 0.211 & 0.0001 \\
\hline
\end{tabular}

In sum, there are some differences in the mobility behavior of native and foreign-born residents. On the whole, the underlying determinants of migration and origin-destination migration flows are similar. Both immigrants and natives react to the underlying migration incentives in the same predictable fashion. For example, unemployed foreign-born residents are more likely to migrate but the same is true for native Swedes. The chief difference, however, lies in the role of the size of foreign-born communities, which may proxy for unique social and economic support networks or immigrant "insider advantages." The relative size of the foreign-born community has an inhibiting effect on an immigrant's willingness to migrate. However, once this variable is taken into account, the foreign born are actually more mobile than native Swedes. Moreover, the mobility-impeding effect of these immigrant networks atrophies with time, perhaps as immigrants become more assimilated. Finally, immigrant migration flows are influenced by the size of foreign-born communities in the destination. That is to say, once an immigrant has made the decision to migrate, the relative size of the foreign-born community in the candidate regions is likely to be an important factor in the destination choice.

\section{SUMMARY and CONCLUSIONS}

This paper is concerned with differences in internal migration behavior between immigrants and natives. By splitting the migration decision into two levels: (1) the decision to migrate and (2) the choice of destination, it is possible to 
identify better the effect of demographic, socioeconomic, immigrant, and regional characteristics on mobility behavior. The paper shows that there are many similarities and a few notable differences in the migration responses of natives and the foreign born. First, although foreign-born and native propensities to migrate are influenced by the same underlying demographic and socioeconomic variables, (e.g., age, household earnings, marital status, family size), the relative size of foreign-born communities in the originating region has some bearing on the migration decision and this influence is more evident for foreign-born groups that are more "culturally distant" from the natives. The relative size of foreign-born communities may be important because it proxies for certain "insider advantages" that are independent of the amount of time invested in developing intimate relationships with members of the community. Second, foreign-born communities may help shape the destination choices of immigrants, once they have made the decision to move. Immigrant migration flows appear to be directed towards regions that have relatively larger foreign-born populations, while native flows appear to be directed away from these same regions.

These results have implications for public policy, regional growth, and modeling practice. The findings that foreign-born migration decisions are so heavily influenced by the size of foreign-born communities and that foreign-born migrants tend to be attracted to labor markets with proportionately larger foreignborn communities suggests that a dispersing settlement strategy such as the "Whole of Sweden" policy is unlikely to be successful in the long term. Immigrants placed in remote, rural municipalities will have a high propensity to migrate into centers with available ethnic networks when they are allowed to do so. The results suggest, furthermore, that interregional macroeconomic econometric models that fail to distinguish between native and foreign-born internal migration flows may introduce some simulation and forecasting error. Although it is relatively straightforward to simulate the effect of different immigrant settlement patterns on regional economic-demographic outcomes with models such as NRIES II (see Isserman 1993 for an example), the dynamics of subsequent internal migration cannot be reproduced because the aggregate data used do not allow one to differentiate between foreign-born and native migration flows. The results here suggest that there will be some tendency for immigrants to perpetuate concentrated initial settlement patterns and for this clustering to be reinforced to some degree by subsequent migration. This immigrant "stickiness" means that the socioeconomic and demographic effects of immigration may be less diffuse than predicted by current models. In a follow-up to this study, simulations will be conducted with the microanalytic simulation model SVERIGE, in order to study the effect of differences in native and immigrant migration behavior on regional economic-demographic outcomes for Sweden. 


\section{REFERENCES}

Andersson, R. "The Geographical and Social Mobility of Immigrants: Escalator Regions in Sweden from an Ethnic Perspective." Geografiska Annaler B 78 (1996), 3-25.

Bartel, A.P. "Where Do the New U.S. Immigrants Live?" Journal of Labor Economics 7 (1989), 371-391.

Beaumont, P., A. Isserman, D. McMillen, D. Plane, and P. Rogerson. "The ECESIS Economic-Demographic Model of the United States." In A. Isserman (ed.) Population Change and the Economy: Social Science Theories and Models. Boston: Kluwer Academic Publishers, 1986.

Belanger, A., and A. Rogers. "The Internal Migration and Spatial Redistribution of the Foreign-Born Population in the United States: 1965-70 and 1975-80." International Migration Review 26 (1992), 1342-1369.

Borgegård, L., and J. Håkansson. "Where is Sweden Multi-Ethnic? The Geographical Distribution of Immigrants on the Municipal Level, 1960-1995." Paper presented at the Annual Conference of the Swedish Association for the Study of International Migration and Ethnic Relations, Stockholm, Sweden, 1997.

Borgegård, L., J. Håkansson, and D.K. Müller. "The Changing Residential Patterns of Immigrants: The Case of Sweden 1973-1992." Yearbook of Population Research in Finland 33 (1996), 173-183.

Clark, W.A.V. "Scale Effects in International Migration to the United States." Regional Studies 30 (1996), 589-600.

Dunlevy, J.A. "On the Settlement Patterns of Recent Caribbean and Latin Immigrants to the United States." Growth and Change 22 (1991), 54-67.

Ehrenberg, R.G., and R.S. Smith. Modern Labor Economics: Theory and Public Policy. New York: Harper Collins Publishers, 1991.

Ellis, M., and R. Wright. "The Balkanization Metaphor in the Analysis of U.S. Immigration." Annals of the Association of American Geographers 88 (1998), 686-698.

Finansdepartementet. Sveriges Ekonomiska Geografi: Bilaga Till Långtidsutredningen. Stockholm, Sweden, 1995.

Fischer, P.A., and G. Malmberg. "Immobility in Sweden: Are those Born in the Baltic Countries Less Mobile than those Born in Sweden or Finland?" Yearbook of Population Research in Finland 34 (1997), 71-86.

Fischer, P.A., E. Holm, G. Malmberg, and T. Straubhaar. Why Do People Stay? The Insider Advantages Approach. Hamburg, Germany: Institute of Economic Policy Research, 1998.

Flowerdew, R., and Boyle, P.J. "Migration Models Incorporating Interdependence of Movers." Environment and Planning A 27 (1995), 1493-1502.

Greenwood, M.J. "Research on Internal Migration in the United States: A Survey." Journal of Economic Literature 13 (1975), 397-433. 
Holm, E., and G. Malmberg. "Micro Representation of Spatial Mobility." Kiruna, Sweden: Spatial Modelling Centre, 1997.

Isserman, A. "United States Immigration Policy and the Industrial Heartland: Laws, Origins, Settlement Patterns and Economic Consequences." Urban Studies 30 (1993), 237-265.

Isserman, A.M., D.A. Plane, P.A. Rogerson, and P.M. Beaumont. "Forecasting Interstate Migration with Limited Data: A Demographic-Economic Approach." Journal of the American Statistical Association 80 (1985), 277-285. Killingsworth, M.R., and J.J. Heckman. "Female Labor Supply: A Survey." In O. Ashenfelter and R. Layard (eds.) Handbook Of Labor Economics. New York: North Holland, 1986.

Kritz, M.M., and J.M. Nogle. "Nativity Concentration and Internal Migration Among the Foreign-Born." Demography 31 (1994), 509-524.

Lange, A. "Flyktingskap, Boende och Agens" (Exile, Housing and Agency). Publication 46, Center for Research in International Migration and Ethnic Relations. Stockholm, 1991.

Lindsay, P.H., and D.A. Norman. Human Information Processing. New York: Academic Press, 1972.

Lundborg, P. "An Interpretation of the Effects of Age on Migration: Nordic Migrants' Choice of Settlement in Sweden." Southern Economic Journal 58 (1991), 392-405.

Moore, E.G., and M.W. Rosenberg. "Modelling Migration Flows of Immigrant Groups in Canada." Environment and Planning A 27 (1995), 699-714.

Newell, A., and H.A. Simon. Human Problem Solving. Englewood Cliffs, NJ: Prentice Hall, 1972.

Norman, D.A., and D.G. Bobrow. "On Data-Limited and Resource-Limited Processes." Cognitive Psychology 7 (1975), 44-64.

Norman, N.R., and K.F. Meikle. "Immigration: The Crunch Issues for Australia." Information Paper IP8. Melbourne, Australia: Committee for Economic Development of Australia (CEDA) Research Department, 1983.

O'Loughlin, J. "The Geographic Distribution of Foreigners in West Germany." Regional Studies 19 (1985), 365-377.

Rooth, D. "Movers and Stayers: An Evaluation of the 'Whole of Sweden Strategy' for Refugee Immigrants and Tied Movers to Sweden." Paper presented at the European Society for Population Economics Conference, Amsterdam, Netherlands, 1998.

Simon, H.A. The Sciences of the Artificial. Cambridge, MA: MIT Press, 1969.

Simon, J.L. The Economic Consequences of Immigration. Cambridge, MA: Basil Blackwell, 1989.

Stillwell, J. "Spatial Interaction Models and the Propensity to Migrate Over Distance." In J. Stillwell and P. Congdon (eds.) Migration Models. London: Belhaven Press, 1991. 
Determinants of the Spatial Mobility of Immigrants: Evidence from Sweden 213

Treyz, G.I., D.S. Rickman, and G. Shao. "The REMI Economic-Demographic Forecasting and Simulation Model." International Regional Science Review 14 (1992), 221-254.

Vencatasawmy, C., E. Holm, and T. Rephann. "Building a Spatial Microsimulation Model." Paper presented at the 11th European Colloquium on Quantitative and Theoretical Geography, Durham, England, 1999.

Walker, R.T., and F. Calzonetti. "Searching for New Manufacturing Plant Locations: A Study of Location Decisions in Central Appalachia." Regional Studies 24 (1990), 15-30. 
